\title{
A INFLUENZA ENTRE NÓS: A INTERIORIZAÇÃO DA GRIPE ESPANHOLA NA AMAZÔNIA E A CHEGADA DA DOENÇA A BRAGANÇA (PA) (1918)
}

\author{
Érico Silva Alves Muniz* \\ Silviane de Carvalho Ferias**
}

\begin{abstract}
Resumo: O presente artigo investiga o surto epidêmico da gripe espanhola e sua chegada à cidade de Bragança (PA), ocorrida entre os meses de novembro e dezembro de 1918. A partir da consulta a bancos de teses e dissertações e artigos científicos buscamos identificar na produção acadêmica as abordagens e enquadramentos possíveis para a história dessa doença. Para o caso de estudo local, utilizamos como fonte neste trabalho o jornal $A$ Cidade, órgão oficial e noticioso que circulava em Bragança (PA) no ano de 1918. Buscamos contribuir com os estudos sobre as epidemias além das grandes cidades, compreendendo a realidade de municípios do interior do país, destacando as colaborações da história local às investigações sobre a história das doenças no Brasil.
\end{abstract}

Palavras-chave: Gripe Espanhola; saúde pública; Bragança (PA).

Abctract: This article investigates the epidemic outbreak of Spanish flu and its arrival in the city of Bragança (state of Pará), which occurred between November and December 1918. After consulting thesis banks, dissertations and scientific articles, we seek to identify in academic production the possible approaches and frameworks for the history of this disease. For the case of local study, we used as source in this work the newspaper A Cidade, official and news organism that circulated in Bragança (PA) in the year 1918. We seek to contribute to studies on epidemics beyond the big cities, understand the reality of municipalities in the interior of the country, highlighting the contributions of local history to investigations on the history of diseases in Brazil.

Keywords: Spanish Flu; public health; Bragança (PA).

\section{Introdução}

O presente artigo aborda a epidemia de gripe espanhola que irrompeu em Bragança, cidade do nordeste do estado do Pará, no início do mês de novembro de 1918. Essa história nos permite verificar como o surto de uma doença pode modificar a estrutura social, cultural e política de uma cidade. Cada sociedade constrói respostas a uma epidemia. Em que diversas formas, em períodos históricos e espaços geográficos característicos, indivíduos e grupos humanos utilizaram-se de signos, práticas e regulamentos para racionalizar, administrar e combater as doenças (Souza, 2007). Desse modo, as pessoas produziram seus próprios modos de definir a etiologia, a transmissão, a terapia apropriada e os significados de uma enfermidade, utilizando-se, para tanto, dos instrumentos disponíveis à época.

\footnotetext{
* Doutor em História. Professor Adjunto da Faculdade de História e do Programa de Pós-Graduação em Linguagens e Saberes na Amazônia do Campus Universitário de Bragança da Universidade Federal do Pará (UFPA). E-mail: ericosilvamuniz@gmail.com ORCID: http://orcid.org/0000-0002-5543-4266

** Mestranda no Programa de Pós-Graduação em Linguagens e Saberes na Amazônia (PPLSA/UFPA). Email: silvianefarias@gmail.com
} 
Seguiremos a perspectiva do estudo sobre a gripe espanhola, primeiro fazendo uma abordagem sobre as produções acadêmicas presentes no banco de dados teses e dissertações registrado na Biblioteca Digital Brasileira de Teses e Dissertações (BDTD) e artigos científicos disponíveis na plataforma Scientific Electronic Library Online (SciELO). E em um segundo momento, apresentamos como a gripe espanhola foi retratada em Bragança, através do jornal $A$ cidade, possibilitando uma análise dos desdobramentos da epidemia em seu cotidiano.

Bragança está inserida no contexto amazônico, região onde os estudos históricos sobre saúde e doença vem aos poucos crescendo, e revelando sua importância. Estes trabalhos nos permitem observar como os sujeitos de determinadas épocas vivenciaram esses conflitos de crise na saúde bem como contam a história de uma sociedade a partir da narrativa da saúde e das doenças. De modo geral, a pesquisa que aqui se apresenta é resultado de análise da literatura sobre o tema e do uso dos jornais com intenção de esclarecer as especificidades da epidemia de gripe espanhola na região amazônica, considerando suas semelhanças e particularidades face a outras regiões e como os sujeitos enfrentaram essa doença avassaladora.

\section{Termos e conceitos: um debate sobre a saúde e doença}

Nesta seção abordaremos no campo da historiografia, discussões sobre a saúde e a doença que se faz necessário, pois nos permite perceber fenômenos históricos em suas dimensões sociais, culturais e políticas. Quando Jacques Le Goff (1985), afirma que as doenças pertencem à história, entendemos que está se referindo a toda história ligada a saberes, práticas, estruturas sociais, instituições e mentalidades que sofreram algum tipo de interferência por meio de uma determinada enfermidade. Inferimos que o entendimento de certa doença pode nos levar ao conhecimento não somente do caráter epidemiológico, mas de toda a estrutura social que está por detrás da história das enfermidades, ou seja, os conflitos sociais, políticos e religiosos, as alternativas e práticas de cura ou ainda quaisquer variáveis que possam colaborar para entender determinado movimento historiográfico.

As assertivas de Laurell (1983) e Abreu Júnior (2018) destacam que o entendimento acerca da saúde e da doença é um movimento de caráter duplo: biológico e social. Os autores evidenciam estes dois elementos reconhecendo as peculiaridades e as relações que cultivam entre si. Sendo assim, a doença reflete entendimentos que nos possibilita visualizar além do sentido biológico, abrangendo uma vasta e grande parte do social.

A discussão atravessará essas duas análises por entendermos que uma reflexão complementa a outra. O fator biológico nos permite compreender as dimensões médicas de como tratar, qual o agente infeccioso, quais os melhores procedimentos adotados perante as enfermidades. Enquanto o caráter social nos possibilita visualizar as variáveis para o acometimento de tal doença em perceber como fatores referentes à moradia, saneamento, instrução, dentre outros são estruturados durante determinado surto epidêmico.

Neste estudo compreendemos estas duas categorias, saúde e doença, não apenas pelo uso do senso comum, mas sim vistas como um fenômeno social que impacta diretamente o cotidiano. Para Silveira e Nascimento (2004) dependendo do período histórico a construção de conceitos e o entendimento sobre a saúde e doença poderiam ter os mais variados significados, influenciados a partir de elementos científicos, culturais, religiosos, sociais e políticos.

Desde os tempos mais longínquos a doença fez parte do cotidiano do homem, na Antiguidade acreditava-se que as doenças estavam ligadas a elementos naturais e/ou sobrenaturais, e suas 
explicações se davam por meio de questões filosóficas ou religiosas. Muitas vezes eram consideradas dentro de um contexto dos climas e estações, onde vários povos da Antiguidade acreditavam que o meio externo era o maior influenciador pela contaminação de uma determinada enfermidade (Rosen, 1994).

Para Czeresnia (2013) a Antiguidade foi fortemente marcada por períodos de pestes. As doenças pestilenciais foram associadas às guerras, invasões, desastres, fome e guardavam uma vinculação religiosa ${ }^{1}$. Muitas representações de epidemias estavam atreladas como castigo divino, e eram simbolizadas em formas de flechas lançadas por deuses embravecidos com as transgressões humanas e que só eram abrandados por meio de sacrifícios e oferendas.

Nesse sentido, muitas doenças acabaram sendo estigmatizadas e o medo perante elas tornou-se um sentimento que transcendia as dores do corpo para se tornar impurezas da alma. As epidemias quando irrompidas causam modificações no cotidiano de uma sociedade, principalmente os espaços de concentrações de pessoas, como nas igrejas, ambientes públicos, locais que promovem eventos e encontros. Por muitos séculos alguns grupos como judeus e os ditos leprosos foram castigados com o peso de serem culpados pelas catástrofes epidêmicas, atrelados a castigos divinos e punição por pecados (Delumeau, 2009).

As epidemias ao longo da história assolaram grandes nações, dizimando as populações e limitando o crescimento demográfico, colocando em xeque em vários momentos a medicina e os saberes médicos, e dessas incertezas as doenças muitas vezes mudaram o curso da história. Para Hamer (1928) o conceito de epidemia baseia-se a partir da ocorrência de períodos naturais que atendiam a peculiaridades e particularidades conformados pelo "espírito do tempo".

O autor destaca ainda a objetividade do termo "constituição epidêmica", analisando um discurso permeado de imagens de uma velha epidemiologia e a construção de novas abordagens nas discussões de surtos epidêmicos ao logo do tempo. Nesse sentido a "constituição epidêmica" relaciona-se com seu próprio acontecimento em sua singularidade, sendo, portanto, sua análise possível de ser ressignificada (Hamer, 1928).

Nas discussões sobre as epidemias torna-se necessário atentarmos para análise dos conceitos sobre saúde e a doença, ambas são expressões das relações mutáveis entre vários componentes do corpo, e sua interação com o ambiente externo, sendo mediada e modificada pela atividade social e pelo ambiente cultural que tal atividade cria (Rosen,1994). Dentro deste debate, destaca-se que a epidemia é uma construção de tessitura mais compacta, de fenômenos constantes e mais homogêneos. Podemos afirmar, portanto, que a epidemia é mais do que uma forma particular de doença. Para Foucault (1977), as chamadas doenças epidêmicas são todas aquelas que atacam ao mesmo tempo e com características imutáveis grandes números de pessoas, esclarecendo ainda que uma doença específica possui um padrão similar de manifestação, enquanto a epidemia não repete inteiramente seus fenômenos biológicos e sociais.

Ou seja, os conceitos de doença e epidemia são construções em que o agente causador de uma epidemia não é exclusivamente o germe, mas sim fatores externos, sociais, sanitários, entre outros, que favorecem a eclosão ou a disseminação dos surtos epidemiológicos. Para Czeresnia (1997), a doença seria uma perturbação do equilíbrio entre as forças que agregam e desagregam o corpo, transcendendo o campo biológico e adentrando o social.

\footnotetext{
${ }^{1}$ Segundo Czeresnia (2013), Heródoto e Tucídides narravam histórias de epidemias que eram acompanhadas de por derrotas de batalhas, perda do rebanho, fome etc. No canto I de llíada, de Homero, a epidemia sobre o exército era figurada em flechas enviadas por deuses.
} 
Quando falamos do fenômeno social da doença, precisamos pensar como a mesma aciona as ideias de medo, morte, estigma, insegurança, dentre tantas outras. É de grande relevância reiterar e instigar o debate acerca da história das doenças e suas relações com o medo. É importante analisar como esse sentimento se destaca nesta discussão sobre saúde e doença, e como essas reflexões nos permite compreender o contexto de determinada época.

Autores como Delumeau (2009) ponderam que o medo é um estado emocional que permite diversos ângulos de abordagens, e nos orienta sobre algumas possibilidades de se estudar essa emoção, apontando ainda sobre um sentido histórico das concepções do medo. Afirma o autor que, o sentido de uma experiência emocional demanda uma investigação das partes falantes, sua cultura, contexto histórico, regras de linguagem, se há usos definidos, entre outras situações mais específicas. Paulatinamente o medo foi sendo construído em um processo histórico, e que sofre variações de uma sociedade para outra. E são essas experiências que irão estabelecer e dar sentidos a que vamos classificar como medo.

Delumeau (2009) destaca que na Grécia antiga o medo era entendido como um castigo dos deuses, e quando se refere à Idade Média atrela ao cristianismo a internalização do medo, a igreja contribuiu quando apontou o medo do demônio e do pecado. Os medos cotidianos das pestes geravam episódios de pânico coletivo, sobretudo quando uma epidemia se abatia sobre uma cidade ou região. Delumeau (2009) descreve várias epidemias e faz uma reflexão desses momentos em que gerava grandes conflitos que aterrorizaram algumas regiões abordas por ele. Uma das epidemias que o autor apresenta é da Itália no século XVII, afirmando que a peste foi uma das causas principais crises daquele século, juntamente com a fome e a guerra.

O medo e a incerteza não nascem apenas da presença da doença, mas também de uma desestruturação de meios que construíam os elementos cotidianos. A população aterrorizada, a política desarticulada, as famílias perdem suas conexões, as ruas suas animações. Quase tudo se reduz a uma grande confusão, atingindo e transformando o evento em calamidade. As pessoas se afligem, uns sofrem pela doença, outras do medo de serem confrontadas com a morte ou com o perigo (Delumeau, 2009).

Outros contextos e outras crises epidêmicas durante passagens de surtos epidêmicos ao longo da história possuem padrões de impacto semelhantes. Delumeau (2009) descreve as epidemias como mal quase de caráter instantâneo, que promove um abalo social, possibilitando que pobres ou ricos, jovens ou velhos sejam acometidos pelo mal. Apesar de muitas epidemias grassarem principalmente nas classes mais pobres, viu expandir-se e atingir personagens mais conhecidos da história. Abreu Junior (2018), desconsidera essa certeza para o caso da epidemia de gripe espanhola, ao demostrar que a enfermidade atingiu sem piedade os moradores de áreas empobrecidas da cidade de Belém, mesmo que tenha morrido alguma pessoa da classe afortunada. Tratando-se das epidemias e do medo que geram, as pessoas temem a contaminação, afastam-se umas das outras, fecham-se em suas casas, nos dias de epidemias os ruídos cotidianos que ritmavam os dias desaparecem de forma repentina.

Para Delumeau (2009), na história das epidemias quando aparece o perigo de contágio, de início procura-se não vê-lo, e as autoridades negligenciam em tomar medidas que o perigo impõe. Dentro desta análise podemos destacar o surto de gripe espanhola no ano de 1918, em que diversas literaturas destacam que muitas autoridades não deram a devida importância quando a gripe começou a grassar (Martins, 2015). O medo legítimo da doença levava a retardar o momento que a epidemia ia ser encarada, contudo chegava um momento em que não se podia mais evitar, é quando o pânico tomava conta dos espaços afetados pela moléstia. 
Com esta breve análise dessas duas categorias, entendemos em parte que o processo histórico de construção sobre saúde e doença, não é linear, e a história delas firmaram-se como um espaço envolvido com fontes no sentido de compreender a sociedade, a cultura, a política e outras dimensões e dinâmicas sociais, traçando perspectivas de construção da historiografia a partir desses estudos. A seguir iremos destacar o levantamento que fizemos sobre a gripe espanhola nas produções de teses, dissertações e artigos, com o intuito de trazer para o debate as possibilidades de abordagem dessa epidemia, observando como o medo estruturou-se como fator determinante no caso da influenza.

\section{Revisando a gripe espanhola: produção em teses, dissertações e artigos.}

Através de levantamento de produções acadêmicas sobre a temática Gripe Espanhola na historiografia é possível observar que o fenômeno vem sendo estudado no Brasil sob diversas perspectivas e aportes teóricos, assim como trabalhos foram produzidos em todas as regiões do país. Para nosso levantamento consideramos os dados sobre teses de doutorado e dissertações de mestrado defendidas em Instituições de Ensino brasileiras, registradas na Biblioteca Digital Brasileira de Teses e Dissertações (BDTD) e artigos científicos registrados na plataforma Scientific Electronic Library Online (SciELO).

Ao levantarmos o estado da arte sobre o tema identificamos aspectos relevantes ao conjunto de análises já produzidas sobre a temática pesquisada, as demandas detectadas pelos autores e a variedade de problemáticas reveladas nas pesquisas indicam que a influenza trouxe consigo mudanças nos aspectos sociais, culturais e políticos das regiões acometidas pela doença. Estes elementos nos possibilitaram construir uma visão geral do que está sendo produzido, ao mesmo tempo em que permitiu identificar as contribuições, avanços e limitações encontradas pelos autores nas produções acadêmicas e científicas pesquisadas.

As pesquisas do tipo "estado da arte” consistem em análises bibliográficas que se destinam a mapear e discutir aquilo que está sendo debatido em determinada área do conhecimento. A revisão literária consiste em um processo de investigação do pesquisador, onde objetiva-se localizar, sistematizar e analisar os estudos já publicados relacionados à sua temática de pesquisa. (Ferreira, 2002).

O estado da arte apresenta uma abordagem em que organizamos os dados de maneira qualitativa por meio de pesquisa bibliográfica. Primeiramente fizemos a organização das produções acadêmicas em Programas de Pós-Graduação em História da seguinte maneira: a) Região brasileira; PPGH; b) Conceito/CAPES. Em um segundo momento, após verificar os conceitos estabelecidos pela CAPES, observamos: a) A distribuição das Teses e Dissertações por Unidade da Federação e Titularidade registrada no banco de dados da Biblioteca Digital Brasileira de Teses e Dissertações (BDTD).

Em seguida, fizemos um levantamento de artigos registrados na base da Scientific Electronic Library Online (SciELO) sobre a gripe espanhola. A escolha dessa plataforma justifica-se por se tratar de uma biblioteca eletrônica que abrange uma coleção seleta de periódicos científicos brasileiros. Segundo Packer e Meneghini (2014), a rede SciELO é a maior provedora de periódicos indexados pelo Diretório de Periódicos de Acesso Aberto (Directory of Open Access Journals - DOAJ), para os autores nenhuma outra região do mundo tem esse nível de adoção de periódicos de acesso aberto indexados internacionalmente.

Ao organizarmos a quantidade de trabalhos sobre o tema desta pesquisa, salientamos que 
o campo de estudos da história das doenças é relativamente novo para a historiografia contemporânea. A ampliação de novas possibilidades de pesquisas e expansão daquilo considerada fonte histórica se deu, sobretudo, a partir da Escola dos Annales $^{2}$ que desde a metade do século XX impôs um marco importante na mudança de concepção sobre o que são fontes. Liderada pelos historiadores Marc Bloch, Lucien Febvre e posteriormente Fernand Braudel, o movimento dos Annales trouxe importantes contribuições no processo de ampliação de possibilidades do que poderia ser uma fonte histórica. Passaram a ser consideradas fontes manifestações culturais, evidências da experiência humana, fontes escritas, orais, audiovisuais, obras de arte, entre outras (Burke, 2012).

Essa nova maneira de se pensar a historiografia ocupa-se com tudo aquilo que homens e mulheres fizeram no passado e fazem no presente, ela considera que existem inúmeras formas de viver e representar o presente. Assim, temas outrora negligenciados pela historiografia passaram a ser objeto de investigação (Burke, 2012).

O surgimento desse modelo historiográfico abriu novas possibilidades e tendências para a historiografia, especialmente a social, cultural e das mentalidades. O pesquisador passa a dialogar, avaliar, questionar e produzir conhecimentos que estão além de meras descrições de documentos e registros, mas sim uma construção historiográfica a partir de novas perspectivas que versam sobre o cultural e o cotidiano, com abordagem interdisciplinar.

Com isso, a história das doenças emerge como um elemento relativamente novo de pesquisa historiográfica que possibilita uma análise dos impactos sociais, políticos e culturais relacionados a uma determinada moléstia. Para Le Goff (1985) as doenças não estão ligadas apenas a uma história dos progressos científicos e tecnológicos, mas por pertencerem "à história profunda dos saberes e das práticas ligadas às estruturas sociais, às instituições, às representações”.

Nas produções acadêmicas analisadas acerca da gripe espanhola, percebemos que as fontes que mais se destacaram foram: atas, fotografias, relatórios médicos, discursos, documentações oficiais e periódicos que circularam na época. As produções convergem na busca de investigar os impactos sociais causados pelo surto de Gripe Espanhola que saiu do domínio biológico para alcançar elementos políticos, culturais e econômicos e que nos casos analisados colocaram em evidências contradições dos discursos higienistas difundidos pelas autoridades da época.

A pesquisa de Gama (2013) busca compreender, por meio dos jornais, como a Gripe Espanhola assumiu dimensões que ultrapassaram os aspectos do físico da cidade de Manaus, que passou de um aspecto puramente de uma patologia corporal, e adentrou em questões políticas, culturais, econômicas e invadiu o imaginário social da população manauara do início do século XX. A autora problematiza os impactos cotidianos que a Gripe Espanhola desencadeou na cidade de Manaus, sobretudo, nas estratégias de sobrevivência que a população desenvolvia para não serem contaminados com o vírus da Influenza. Segundo Gama (2013), a passagem da Gripe Espanhola em Manaus revelou também que, a cidade outrora "moderna" impulsionada pela economia do látex, mostrou-se vulnerável a uma doença que chegava silenciosa, mas que causou uma série de mortes e que colocaram em xeque os discursos higienistas e sanitários promovidos por políticos

\footnotetext{
2 Na França, os anos de 1920, testemunharam um movimento rumo a um novo tipo de história, conduzido por dois professores da Universidade de Estrasburgo, Marc Bloch e Lucien Febre. A revista fundada por eles, Annales d'Histoire économique et sociale (Anais de História Econômica e Social), fez críticas implacáveis a historiadores tradicionais (Positivistas). Febvre e Bloch, dedicaram-se ao predomínio da história política (Burke, 2012). Segundo Burke (2012), Febvre e Bloch ambicionavam estabelecer uma história mais ampla e mais humana, que abrangeria todas as atividades humanas e estaria menos preocupada com a narrativa de eventos do que com a análise das estruturas, termo que se tornou o preferido de historiadores franceses da chamada "Escola dos Annales" (Burke, 1990).
} 
que detinham o controle da imprensa.

Olinto (1995), por sua vez, investiga as contradições dos discursos de modernidades na cidade do Rio Grande (Estado do Rio Grande do Sul), no período em que houve o surto de Gripe Espanhola no Brasil. A autora também destaca as fragilidades dos projetos de modernidade para a cidade pesquisada, salientando que a doença despiu as mazelas sociais contrapondo a imagem de uma cidade salubre e livre de moléstias. Ao analisar os periódicos e os documentos oficiais da época, Olinto (1995) constrói sua análise historiográfica sobre a doença dentro da perspectiva do medo. A autora destaca as mudanças ocorridas na cidade após o surto da Influenza. A população buscava meios de sobreviver à moléstia, e estes meios não se davam necessariamente por nenhum saber científico, por nenhum conhecimento novo ou técnica recém-descoberta, pois a modernidade havia se demonstrado frágil diante de uma velha epidemia. Os discursos haviam sido quebrados, a Gripe Espanhola mostrou as contradições do moderno.

A pesquisa de Damascena Neto (2011) investiga a sintomatologia da Gripe Espanhola na cidade de Goiás, bem como ressalta a imprecisão da medicina em definir e caracterizar a doença. Para tanto, o autor ancorou-se nos registros da imprensa goiana, que, no contexto de 1918/1919, foram dirigidos à população e denominados Conselhos ao povo; ou seja, eram indicações das autoridades sanitárias para o combate da gripe espanhola. Mais que um problema biológico, a gripe espanhola se tornou um problema social, e como tal a pesquisa analisou a doença a partir de aspectos sociais. Ao historicizar a doença, o autor construiu uma análise social da gripe espanhola na cidade de Goiás. Para ele as medidas sanitárias adotadas na capital eram diferentes das medidas adotadas no interior, a atenção das autoridades era mais evidente na capital do Estado. Demonstrou-se, por meio dos jornais e outras fontes, as formas pelas quais a gripe espanhola quebrou a rotina da sociedade goiana, no período que ele denominou de "cotidiano epidêmico".

Silva (2012) aborda como a cidade de Manaus no final do século XIX e início do XX, sentiu um crescimento populacional em decorrência da exploração da borracha, e com isso a chegada de migrantes para a cidade. E com o aumento populacional Manaus começou a vivenciar várias epidemias, abordando ainda as transformações sociais e uma discussão sobre a saúde pública bem como a estrutura da saúde na cidade de Manaus. A gripe espanhola em 1918, foi um grande bloqueio para a cidade, principalmente na economia e na saúde. A influenza foi um grande desafio pelo alto índice de mortalidade, mas as ações para o combate não divergiam das que foram realizadas no restante do País.

Abreu Junior (2018) investiga como a pandemia de gripe espanhola atingiu o município de Belém, e suas consequências biológicas, culturais e sociais da sua rotina. O autor destaca como aspectos do medo trouxeram mudanças no cotidiano da capital paraense durante a passagem da influenza, apresentando como fontes da pesquisa jornais, relatórios oficiais, relatos de memorialistas e documentos médicos. A pesquisa aponta que diante da pandemia muitos mecanismos de prevenção da doença foram estabelecidos, seja por ações sanitaristas do poder público, ou por estratégias desenvolvidas pela população para não ser acometida pela doença. Segundo Abreu Junior (2018), as práticas culturais de cura e religiosas se acentuaram nesse contexto. No viés econômico muitos aproveitaram-se da situação para se beneficiar financeiramente com a venda de caixões, remédios entre outros.

O autor conclui que a passagem da gripe por Belém correspondeu a um acontecimento com conexões globais, no entanto, com particularidades locais. O autor destaca que na capital paraense não se percebeu disputas entre a medicina alopática e as práticas de cura, tal como ocorreu 
em outras regiões. A situação precária da maior parte da população e a falta de respostas dos médicos, ao menos durante os dias que a gripe grassou, fez com que esculápios não conflitassem com a chamada medicina popular.

A pesquisa de Dalla'ana e Mota (2017) investiga as tensões surgidas durante a epidemia de gripe espanhola na cidade de Sorocaba (SP), ocorrida no final do ano de 1918. Os autores utilizam como fonte as narrativas repercutidas pela imprensa local, tomando como estudo de caso a fábrica Santa Rosália. O episódio curioso desta pesquisa envolveu a recusa de seu proprietário da fábrica supracitada em manter a interrupção dos trabalhos, no auge da crise epidêmica, mesmo sob a determinação do poder municipal de Sorocaba. Os autores buscam ainda contribuir com estudos sobre as epidemias nos municípios do interior do país, ressaltando as colaborações da história local às investigações sobre a história das doenças no Brasil.

$\mathrm{Na}$ produção seguinte, Bertucci (2009) argumenta que na passagem da influenza em algumas cidades do Brasil o medo tornou-se um sentimento onipresente nas cidades acometidas pelo surto da Gripe Espanhola. Para ela, a doença motivou tanto a discriminação e a exclusão, quanto a procura por meios alternativos de práticas de cura já que a Influenza desafiou o saber médicocientífico. A doença proporcionou que emergissem práticas caseiras de cura que, combinadas com as informações médicas e com a fé, traduziram a generosidade de indivíduos que difundiam gratuitamente aquilo que acreditavam, ou seja, que poderiam acabar com a moléstia. Para Bertucci (2009), o cotidiano dos brasileiros de norte a sul do Brasil foi modificado pelo surto epidêmico da gripe, locais públicos foram fechados, houve a proibição de aglomerações de pessoas, tudo que evitasse a proliferação da doença.

A pesquisa de Brito (1997) investiga também os impactos psicológicos e sociais da epidemia na cidade do Rio de Janeiro, em que foi abordada inicialmente como um fenômeno cultural e social relacionado às atitudes a representações coletivas sobre a doença e a morte. Segundo a autora, o sentimento de medo é transmitido culturalmente e incide rupturas que afetam a vida cotidiana e advertem a convivência social. Esses anseios, angústias, sensação de impotência, dentre outros, são recorrentes nesse momento de incerteza perante uma epidemia, em que a vida parece perder os parâmetros de uma normalidade. Segundo Brito (1997), o medo aparece como um sentimento duradouro. E a gripe espanhola tornou-se o motivo para que o aflorasse vigorosamente, e motivos não faltam para tal relação de sentido: a velocidade com que a doença avançou a quantidade de doentes e mortos que produziu, a desordem urbana e social que produziu, traduzindo-se, por exemplo, no espetáculo macabro de cadáveres jogados às ruas por falta de caixões e sepulturas, suscitando indignação e medo na população.

Percebemos que Dalla'ana e Mota (2017), Bertucci (2009) e Brito (1997) transcorrem sobre elementos do cotidiano após o surto da Influenza e na maneira com que foram remodelados alguns costumes de determinada cidade. Um ponto de destaque levantado pelos autores, principalmente por Bertucci (2009) e Brito (1997), foi o sentimento de medo que a moléstia trouxe consigo e que passou a remodelar as relações interpessoais que ora servia para excluir e discriminar o enfermo, ora servia para possibilitar que novas práticas de cura surgissem pelo conhecimento popular.

O avanço do número de doentes e mortos proporcionou uma ruptura na vida cotidiana, gerando diversos conflitos, sobretudo entre as elites e as autoridades. Nesse sentido a pesquisa de Souza $(2005 ; 2007)$ investiga por meio da imprensa escrita, o surto epidêmico da gripe espanhola na cidade de Salvador (BA), destacando os aspectos sanitários da capital da Bahia e as fragilidades das políticas de saúde e assistência pública oferecida pelo Estado. Na pesquisa a autora salienta que a doença descortinou aspectos de uma sociedade complexa e desigual que foi atingida diretamente 
pela epidemia. Um ponto interessante é que a autora mostra também como o medo de ser acometido com a doença estremeceu as relações entre as elites e as autoridades baianas. As elites sentindose ameaçadas ao notar que a epidemia estava alcançando toda a população, buscaram por meio da imprensa pressionar as autoridades para que tomassem medidas cabíveis.

Souza (2005) procura identificar aspectos político-sociais da cidade de Salvador, principalmente por meio dos periódicos da época, o jogo de poder, as condições sanitárias da capital, e as fragilidades principalmente de assistência médica para com a sociedade complexa e desigual que foi evidenciada pela epidemia. Segundo Souza (2007), as autoridades baianas pareciam considerar distante a probabilidade de que um mal que grassava em lugares tão afastados do Brasil pudesse vir a vitimar também o povo baiano. Mesmo quando os primeiros boatos da existência de uma epidemia de gripe em Salvador começaram a circular havia o desinteresse das autoridades em informar a população que a doença avançava na cidade, tratando-a apenas como uma enfermidade de pouca periculosidade. Portanto, em um primeiro momento, o governo baiano, assim como os governantes de outras partes do Brasil, assumiu uma postura passiva, propalando a benignidade da doença.

Do ponto de vista médico sanitarista, Souza (2009) evidencia os desafios encontrados pelo avanço inesperado da moléstia em Salvador. As incertezas e as controvérsias do diagnóstico agitavam a comunidade acadêmica e científica mundial. A autora analisa o posicionamento da medicina baiana diante dessas discussões e o aporte científico utilizado pelos médicos para explicar o evento epidêmico e recomendar as medidas terapêuticas e profiláticas a partir do conhecimento científico.

O desconhecimento patológico da doença causava diversas discussões sociais, políticas e sanitárias, ao mesmo tempo em que a moléstia avançava desenfreadamente alcançado diferentes camadas sociais, no entanto, a doença certamente atingia as pessoas que estavam nas camadas mais baixas, pela falta de estrutura, falta de alimentação, acesso a tratamentos médicos, dentre outras variáveis que pesam para que o índice de mortalidade seja maior em um determinado grupo social.

Nesse sentido, Silveira (2005) afirma que em 1918, quando a pandemia da gripe espanhola começava a aumentar, a comunidade médica continuava mergulhada nas mesmas controvérsias a respeito da causa e da profilaxia da influenza. A autora investiga a mobilização da classe médica diante da impossibilidade e incerteza dos laboratórios de esclarecer a verdadeira face daquela doença, o que levava a muitas vezes o diagnóstico de outras enfermidades.

Dos poucos conhecimentos que se tinha sobre a gripe espanhola a principal certeza era da sua grande difusão e contágio, e o fato de apresentar sintomas variados impedia a identificação dos primeiros casos o que dificultava a tomada de qualquer medida preventiva. Algumas abordagens historiográficas buscam analisar as relações existentes entre o estado, o saber médico, as políticas de saúde pública e as representações das doenças para com as pessoas.

A pesquisa de Bertucci (2004) analisa a epidemia de gripe espanhola em Campinas (SP), investigando o contexto social da doença, que trouxe uma desorganização dos espaços sociais da cidade. As consequências promovidas pela gripe foram tão marcantes que a autora destaca que muitas vezes quem não morria da gripe, era vitimado por uma de suas consequências, como por exemplo, a fome. Do ponto de vista econômico, a cidade de Campinas passou por um período em que muitos gêneros alimentícios inflacionaram, pois, muitos estabelecimentos fecharam o que deixou o acesso a produtos perecíveis mais difíceis e onerosos.

A vida em muitas cidades do país acabou sendo afetada pela doença. Diversas medidas foram tomadas consideradas preventivas, como evitar apertos de mão, abraços ou beijos, foi insistentemente divulgado. Para diminuir ainda mais o número de aglomerações, missas, cultos e demais reuniões de caráter religioso foram drasticamente reduzidos. 
Goulart (2005) analisa por meio dos registros da imprensa carioca e de conjuntos documentais que incluem anais, relatórios e boletins de um ministério, da Prefeitura da cidade e da Câmara dos Deputados, bem como estudos da Academia Nacional de Medicina e teses da Faculdade de Medicina a utilização da epidemia como mecanismo de engenharia política. A autora identifica os seus impactos sobre a representação de alguns atores políticos e sociais do período, bem como sobre a reafirmação de um grupo de higienistas como intelligentziia, com vocação para a liderança política e peça fundamental no processo de modernização da sociedade brasileira.

Goulart (2005) destaca que ao longo da epidemia, os jornais e alguns deputados da Câmara desencadearam um processo de valorização do papel dos higienistas, dos homens de laboratório, como únicos detentores de um conhecimento específico para salvar a sociedade e para resolver os problemas sanitários do país. Diante do cenário instaurado pela influenza, esses homens, com sua arte, se transformaram em modelo ideal de administradores para a saúde pública.

A pesquisa de Goulart (2005) proporcionou dois movimentos distintos para a gripe espanhola: o primeiro foi que a epidemia acarretou uma série de insatisfações com a atividade política das elites governantes e com suas políticas sociais; segundo, possibilitou um maior controle sobre a medicina oficial, acabando por transformar os grupos de higienistas nos únicos atores capazes de encontrar uma solução para a crise instaurada pelo surto epidêmico da Influenza.

O fato é que a doença trouxe a ocorrência de óbitos entre todos os grupos sociais e acabou fazendo com que se alimentasse uma visão democrática sobre a espanhola. Contudo, a pesquisa de Bertolli Filho(2009) adverte que a gripe se desenvolveu de acordo com o padrão de mortalidade de cada grupo social, a moléstia foi especialmente violenta em áreas que apresentavam deficiente estrutura sanitária, como os subúrbios e cortiços espalhados pela cidade, e sobre indivíduos com deficiências nutricionais e de saúde.

Diante do exposto, percebemos que a gripe espanhola transcendeu seus aspectos biológicos, alcançou níveis sociais, culturais, econômicos e psicológicos que redefiniram relações cotidianas. A influenza mostrou as mazelas sociais e a ineficácia de muitas políticas higienistas colocando em dúvida os discursos de modernidade, típicos da época. Os jornais, documentos oficiais e fotografias foram as fontes mais utilizadas pelos autores das produções investigadas.

A importância de realizar a revisão de literatura sobre essa temática nos ajudou a ter um panorama do atual estado do conhecimento sobre o tema pesquisado. Este levantamento permite perceber as contribuições das pesquisas existentes, levando-nos a identificar pontos necessários que ainda carecem de investigação do ponto de vista historiográfico. Na sequência faremos uma discussão do surto da influenza na cidade de Bragança (PA), onde apresentaremos as análises e observações feitas dos jornais que circularam na cidade em 1918, ano do surto mais grave que se tem notícia.

\section{A gripe espanhola nos jornais bragantinos}

O ano de 1918 foi marcado por inúmeras tragédias como a guerra, e neste contexto uma grave epidemia se apresentava. Devastando cidades e ceifando vidas em diversas regiões do mundo. A gripe espanhola como ficou conhecida foi uma das mais graves epidemias já registrada na história. O primeiro contato de brasileiros com a gripe, teria sido os integrantes médicos que atuaram na Primeira Guerra Mundial, acredita-se que a doença foi trazida por um navio inglês o Demerara, que passou em alguns portos como o de Salvador, Recife e rio de Janeiro. Logo, segundo Bertolli Filho (2003), essas cidades já estavam tomadas pela moléstia. 
A chegada da gripe no Pará, mais especificamente em Belém, segundo o autor Abreu Júnior (2018), foi no início de outubro do ano de 1918. Belém já registrava algumas notícias que a espanhola já se apresentava na capital, um navio vindo do Rio de Janeiro aportava na cidade e muitos passageiros possuíam alguns sintomas da enfermidade. Logo após esse episódio, a imprensa paraense passou a divulgar com frequência situações referentes à moléstia, a situação rapidamente se agravou, avançando para outras cidades paraenses. As informações sobre a doença eram muitas vezes desencontradas, tanto pelo fato de pouco se saber da doença, bem como pela necessidade de abrandar os fatos para evitar o pânico da população. No entanto, não havia mais como esconder que a doença havia tomado conta de diversas cidades da Amazônia, inclusive o nordeste paraense, sendo a cidade de Bragança uma delas.

Bragança vivia neste momento um processo de desenvolvimento econômico, a partir do crescimento econômico da capital Belém com a exploração da borracha, que influenciou em diversas cidades paraenses, e Bragança pelo transporte terrestre e marítimo sofreu grandes impactos que influenciou no desenvolvimento produtivo e espacial da cidade. E por ser uma cidade portuária, está variável favorece em alguns sentidos. Mas, também revela a outra face da cidade que é a porta de entrada para as doenças por meio do ir e vir das embarcações. Particularmente as cidades portuárias eram as portas de entrada para diversas moléstias, por essa característica configurava um caminho inevitável para a temida gripe espanhola, e a cidade de Bragança, também portuária começa apresentar os primeiros sinais que a gripe já circulava na urbe.

Situada à margem do rio Caeté, Bragança é uma das cidades mais importantes da zona bragantina. No início do século XX o setor comercial estava prestes a ser ligado à ferrovia que foi construída com a finalidade de escoar a produção agrícola para a capital Belém, a Estrada de Ferro foi de grande relevância para o crescimento de diversos setores, juntamente com a extração do látex que respingou na cidade e o processo de colonização e imigração advindo da construção da ferrovia. (Nonato da Silva, 2006)

A cidade de Bragança vinha apresentando mudanças significativas, marcadas pelo crescimento do seu núcleo urbano e de uma relativa diversificação de atividades econômicas, lojas, farmácias, fábricas e outros setores se juntavam ao comércio de produtos advindos principalmente da agricultura. A Estrada de ferro era um dos ícones deste contexto histórico, marcou a história da urbe, o sonho da tão aguardada ferrovia que foi inaugurada em 1908 teve seu final em 1965.

Em meados do ano de 1918, a cidade vivencia uma grande crise de saúde pública, com a chegada da epidemia que grassava mundo afora. A notícia da gripe espanhola em Bragança se dá por meio das páginas da imprensa, primeiro de forma tímida, sem muitos detalhes e com um ar de que tudo estava sob controle. No dia 03 de novembro de 1918 o jornal " $A$ Cidade” noticiava que a influenza já se fazia presente na cidade de Bragança:

\footnotetext{
A influenza entre nós

Já se tem manifestado na cidade alguns casos de influenza, felizmente sem gravidade.

- o coronel intendente municipal mandou interdictar hontem (commemoração dos mortos) o cemitério publico desta cidade, das 512 horas da tarde em diante, afim de evitar aglomerações e o consequente aglomeramento do mal.

- terminaram em 31 do passado os exames no grupo escolar "Corrêa de Freitas e nas escolas municipaes do interior, realizados antes da epocha legal como preventivo à invasão da "hespanhola”.
}

\footnotetext{
3 O jornal "A Cidade" era um órgão oficial de informação da intendência municipal, teve sua primeira edição publicada em junho de 1915, com publicação nos dias de domingo.
} 
- Devido a propagação da "hespanhola" o coronel intendente telegrafou ao ao dr. Governador e diretor de higyene do Estado, pedindo um medico e ambulância. Hotem s. s. recebeu do dr. Governador telegramma, avisando de que já havia providenciado para que fosse satisfeito se pedido. Tambem s. s. recebeu do dr. Albino Cordeiro, director da higyene comunicando-lhe que a ambulancia viria $4^{a}$ feira e tinha dado ordens para que aqui viesse estacionar o dr. Bruno Bittencourt, que se acha em Vizeu. ${ }^{4}$

Durante o mês de novembro já se tinha notícia da gripe em Bragança. A enfermidade já era realidade na cidade, tanto que o Coronel Intendente enviou um telegrama ao então Governador e Diretor de Higiene do Estado solicitando médico e ambulância. Percebe-se nesta nota que havia um ar de preocupação, tanto que algumas atividades foram interrompidas, com o desenrolar dos fatos, as transformações da vida urbana, foram aumentando junto com o temor, e a intensificação de informações na imprensa foram crescendo.

As autoridades já tinham conhecimento que a gripe circulava na cidade, no entanto, as declarações sobre a enfermidade eram de não criar desespero na população, associando os casos como uma simples gripe. De início a ideia de não aterrorizar a sociedade surtiu efeito, mas na tiragem seguinte do jornal o discurso havia sofrido alteração, a gripe era grave e a situação era de calamidade. Em 10 de novembro de 1918 o periódico oficial da administração municipal trazia em sua primeira página informes para que se cancelassem diversas atividades na cidade, desse momento em diante o noticiário referente a espanhola passou a ocupar mais espaço nos periódicos locais, como se observa:

\section{Tiro de Guerra 596}

O sargento Messias, instructor do Tiro de Guerra 596, recebeu do sr. Capm. Moura Carvalho, inspector regional, telegramma, mandando que devido o nosso estado sanitário, fossem suspensos os exercícios militares, até segunda ordem.

\section{Os doentes}

Estão já em franca convalescença, os nosso amigos dr. Lima Mendes, Benedicto Athayde, Ramiro Guimarães, Rodrigues Pinagé e Joaquim Dias, empregado do srs. J. Adonias \& Comp. ${ }^{2}$. Está acamado, desde $5^{a}$ feira o nosso amigo Filenillo Ramos, sendo lisonjeiro o seu estado. Os demais gripados, estão melhores.

\section{"FOOT-BALL}

O coronel intendente municipal, pediu ao presidente da Liga de Sports Terrestres, desta cidade a suspensão do capeonato de foot-ball, como preventivo a propagação da gripe.". ( A CIDADE, 10 de novembro de 1918,p.1)

Através dessa notícia do jornal podemos perceber não apenas uma preocupação da intendência municipal com a questão da saúde, mas também uma tentativa de que a gripe não se disseminasse na cidade, uma vez que, o aglomerado de pessoas poderia facilitar a propagação da moléstia, essas e outras notícias foram pululando na imprensa bragantina. A Bragança que outrora estava se desenhando para o moderno não ficou imune à gripe.

Como é de se imaginar, a doença seguiu fazendo vítimas, e os jornais a cada tiragem traziam novas informações, a morte pela gripe espanhola foi aos poucos sendo incorporadas ao cotidiano bragantino. Esses comunicados que apareceram nos jornais, foram praticamente semelhantes nos espaços onde a gripe estava presente, como afirma Abreu Júnior (2018) que na cidade de Belém o então intendente municipal, Henrique Santa Rosa, baixou uma portaria que proibia a visitação nos cemitérios no dia dos finados, afim de se evitar aglomerados e por consequência o aumento de

\footnotetext{
${ }^{4}$ A cidade, 03 de novembro de 1918. P.3
} 
enfermos.

Para Silveira (2005) quando em 1918 a espanhola começava expandir-se, os grupos médicos permaneciam em meio as controvérsias da doença e de sua profilaxia, além das incertezas que caracterizavam o saber médico, e os colocava em xeque, as dúvidas eram frequentes sobre a verdadeira natureza da moléstia, e o diversos sintomas muitas vezes eram confundidos com outras doenças.

Nesse período de grande crise na saúde, houve diversas situações que envolveram questões sociais, econômicas e políticas, muitas autoridades tiraram proveito deste acontecimento para autopromoção de sua imagem. Um fato que aconteceu nesse período foi um telegrama enviado a intendência municipal pelo jornal "Folha do Norte", a respeito da situação que se agravava em relação a cidade de Bragança, o telegrama trazia as seguintes informações:

\begin{abstract}
"Alastra assustadoramente a influenza, existindo mais de 80 casos na cidade. No interior do município eleva-se a mais de 200 os números de gripados. Falleceu o cabo do destacamento local. Os presos acham-se todos acommettidos do mal e vão morrendo à mingua de socorros, porque a intendencia não lhes dá recursos.

A fabrica Adonias, fechou por estar todo o seu pessoal doente. A pharmacia local encontrase balda de recursos. O prefeito de policia pedio providencias aos poderes competentes." 5
\end{abstract}

Este telegrama foi bastante provocador para a intendência municipal de Bragança. Os discursos das autoridades eram desencontrados o que gerava ainda mais conflitos políticos, e pouco movimento no sentido de contornar a situação. E, nesse sentido, as autoridades bragantinas logo se pronunciaram sobre o assunto, afirmando ser mentira o que a "Folha do Norte" havia declarado.

"Existem actualmente na cidade uns 120 grippados, e todos elles tem tido assistencia medica,
quer particular, quer dada pelo Estado ou pelo municipio .[...]
O que mais concorreu para a propagação do mal na cadeia publica, foi a falta de hygiene que
lá se nota, bem como pode atetstar o dr.Mendes. Aos presos tem sido dado pelo municipio
elementos e remedios de que carecem não tendo ate fallecido. O que nos admira, é certas
pessôas descerem a fazer politica com cousas serias, quando melhor fariam se corressem com
seus exforços para ajudarem os poderes publicos a debellar o mal que nos ataca.
Ficou plenamente demonstrado ser infundada a accuação que o correspondente da "Folha",
fez ao coronel intendende, o que alias não nos admirou, pois já estamos acostumados com
isso.
O publico que julgue." ${ }^{6}$

Essa nota de jornal nos permite verificar que as questões das lideranças políticas estavam sempre atreladas aos fatos recorrentes na cidade, e este ano era marcado por disputas eleitorais, o que pode ter contribuído para tal situação. As rupturas eram tantas que a própria intendência apresentava informações desencontradas, primeiro divulga um número "oficial" de 120 pessoas acometidas pela doença, em seguida justifica que a propagação na cadeia pública se deu devido a falta de higiene.

Com essa situação foi colocada em xeque o discurso oficial sobre as questões de saúde, de saneamento e de que a cidade encontrava um estado de insalubridade, Bragança enfrentava uma das maiores crises sanitárias. A gripe espanhola desnudou as carências sanitárias das cidades e o limite do saber médico oficial. O tempo da epidemia é o da solidão, da suspeição generalizada, com

${ }^{5}$ A cidade, 10 de novembro de 1918. p.1

${ }^{6}$ A Cidade, 10 de novembro de 1918, p.1 
o esgarçamento das relações humanas expondo de maneira cruel o egoísmo e a fragilidade do homem. Bertucci (2004, p.114)

Declarado o estado epidêmico, o intendente tomou algumas medidas para que se pudessem limitar a contaminação e diminuir as consequências da gripe, publicando na imprensa um comunicado que estava interditado o cemitério para visitas, a fim de limitar o contágio. Desta maneira, as rupturas impostas à vida cotidiana por conta da epidemia obrigaram as autoridades a lançar estratégias de caráter coletivo para combater o mal da influenza por meio de cuidados com a higiene, a doença espalhava-se rapidamente, subtraindo as pessoas de suas famílias, seus trabalhos e da cidade; a inquietude e a angústia próprias de tempos de epidemias já imperavam nas cidades.

Assim, na tentativa de modificar os hábitos da população, o governo municipal da cidade de Bragança tenta "ensinar bons hábitos" a população, e o uso do jornal foi de grande relevância para a Intendência Municipal no que tange a busca de condições para evitar ainda mais o alastramento da gripe. Diante do pânico que a gripe parecia causar na cidade diversas medidas foram tomadas como forma de prevenção contra a doença. Os veículos de comunicação como os jornais foram usados com o intuito de noticiar, educar e instruir a população sobre como evitar e combater a influenza. Destacamos uma nota do referido jornal em que se publicaram conselhos médicos, esses conselhos buscavam conscientizar a população para os cuidados com os doentes e tentar conter o avanço da doença:

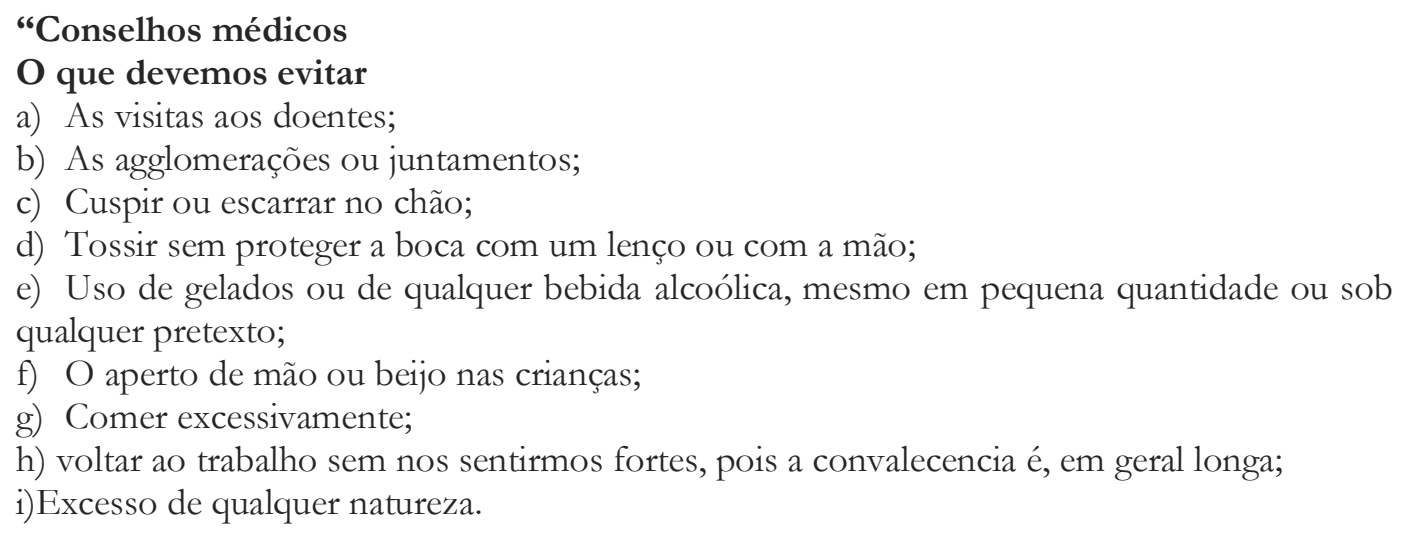

\section{O que devemos fazer}

a) Lavar frequentemente a casa com solução de creolina;

b) Abrir largam, ente as janellas e portas dos aposentos, pois casa em que entra o ar não entra a doença;

c) Escarrar dentro de pequenas bacias com conteúdo de solução de creolina;

d) Escarrar nos lenços, quando não tivermos bacia ou escarrador

e) Ferver os lenços;

f) Comer sobriamente evitando gelados e bebidas alcoolicas;

g) Sobrevindo qualquer complicação, chamar o médico mais próximo.

Posto medico da Associação Commercial do Pará, novembro de 1918-(aa) Dr. J.A. de Magalhães, dr. Gelminez Gomes."7

Salientamos nesta nota de jornal que em meio a este cenário assustador algumas medidas foram tomadas com a intenção de evitar a disseminação da doença por toda cidade. Salientamos nesta nota de jornal que estes conselhos são dados pelo posto médico da associação Comercial do Pará, isso quer dizer que as condições do comércio da cidade estavam abaladas, possivelmente

7 A Cidade, Bragança, 10 de novembro de 1918. p.04 
havia um grande número de trabalhadores acometidos e que de certa forma iria atingir o mercado como um todo.

A gripe espanhola alterou drasticamente o cotidiano dos bragantinos desde que a doença se tornou uma ameaça iminente para a cidade. Quando os primeiros boatos surgiram, Bragança foi aos poucos transformando-se no espaço de doença, cheios de armadilhas que favoreciam contágio, e o que restava era seguir as recomendações das autoridades e tentar ao máximo se resguardar deste mal, a paralisação de diversas atividades denunciava a grave epidemia que chegava na urbe.

A imprensa ainda trazia, informações dos possíveis sintomas e dos medicamentos para tratar a gripe:

Ao sentirmos a ameaça do mal, que se inicia por dôres no corpo, vermelhidão do olhos, forte dôr na cabeça, aperto de garganta, tomar immediatamente um purgativo de sulfato de magnésia (Sal amargo), e a seguir de 2 em 2 horas uma capsula com a seguinte composição;

$$
\begin{array}{ll}
\text { Asperina } & 1 \text { áá } \\
\text { Pyramidon } & 10,15 \\
\text { Guaraná em pó } &
\end{array}
$$

até passarem a febre e diminuir as dôres do corpo e da cabeça. Contra a tossi, que geralmente apparece no $2^{\circ}$, ou $3^{\circ}$ dia, tomaremos qualquer xarope dos annunciados contra a tossi ou bronchite ou a seguinte formula:

codeina ….......... 0,20

xarope de ipeca....10,0

agua de louro cereja 10,0

xarope de balsamo tolú áá

xarope de fls de laranja .....100

F. s. a. para tomar uma colher de $3 \mathrm{em} 3$ horas

Posto medico da associação Commercial do Pará; novembro de 1918-(aa) Dr. J. $\quad$ A. de Magalhães,dr. Gelminez Gomes ${ }^{8}$

Notamos que esses conselhos tentavam fazer com que a população criasse hábitos tanto de higiene tanto como de cuidados para o não alastramento da doença, pois a gripe espanhola estava invadindo a cidade, e a imprensa estava trazendo notícias frequentes sobre a gripe em quase todas as suas tiragens, é o que se observa nos jornais dos meses de novembro e dezembro do ano de 1918.

E tratando-se de gripe, as medicações eram mais ou menos padronizadas, isto é, os médicos usavam fórmulas semelhantes para os casos de gripe, seja a influenza ou outras já conhecidas. Para Sontag (2007), quando uma doença é explicada por uma variedade de causas, é exatamente uma reflexão de que sua origem não é realmente compreendida. Portanto, sem uma causa bem determinada, as possibilidades terapêuticas se tornam quase que infinitas. Acrescentando o fato de nossa pesquisa aborda a realidade de uma cidade amazônica, onde o uso de plantas, ervas, chá e outras formas das artes da cura faziam-se presentes.

Bertolli Filho (2003) e Damacena Neto (2011), destacam que de forma ampla os jornais durante a passagem da influenza, divulgavam produtos que preveniam e combatiam a enfermidade, sendo que era uma estratégia muito comum nos anúncios os destaques dos preparados, e que raramente apresentavam sua composição.

Um fato comum presente nas literatura sobre a gripe espanhola, é a exploração dos comerciantes, farmacêuticos dentre outros setores para a venda de seus produtos, como observamos na

8 A cidade, 10 de novembro de 1918. 
nota acima que para combater a tosse pode tomar qualquer xarope que está veiculado no jornal, os medicamentos até então usados para combater, bronquite, tosse bem como outras doenças associadas ao pulmão, agora são ressignificados como úteis a cura da gripe.

\section{Considerações finais}

Este artigo buscou trazer uma abordagem sobre a gripe espanhola. Por meio da literatura produzida no Brasil, com grande relevância para o construção do conhecimento sobre saúde e doenças, e por meio do diálogo entre as literaturas, nos permitiu traçar abordagens para o estudo da gripe na cidade de Bragança (PA), fazendo assim, uma leitura sobre a epidemia na cidade, destacando as rupturas causadas por uma grave crise na saúde pública, mas que resvalou e todos os setores da sociedade bragantina.

Neste estudo o levantamento e entendimento das literaturas nos possibilitaram construir uma visão geral do que está sendo produzido, ao mesmo tempo em que permitiu identificar as contribuições, avanços e limitações encontradas pelos autores nas produções acadêmicas e científicas pesquisadas.

Para Nonato da Silva (2006), no início do século XX em Bragança e diversas localidades do Brasil foram cenários de vários movimentos sociais e culturais, com grande alcance social graças a ação da escrita e da imprensa. E neste momento quando a epidemia de gripe atingiu Bragança, em novembro de 1918, a imagem que a cidade estava construindo tornou-se bem diferente no final deste mesmo ano. O surto epidêmico ameaçou todos os setores sociais, políticos e culturais, a influenza colocou em xeque o ideal de cidade que Bragança estava traçando, expondo as fragilidades da saúde pública local.

Sendo assim, entendemos que é necessário o estudo da história local, para a contribuição das pesquisas sobre as epidemias no País, proporcionando a escrita de uma historiografia redirecionando o foco das análises das grandes cidades para as cidades do interior, enfatizando suas particularidades e sua participação na história do Brasil. A passagem da gripe espanhola em Bragança certamente se deu com conexões globais, já que a enfermidade grassou em praticamente em todo o globo. Durante a sua passagem ficou claro que as autoridades locais de início, entendiam a doença como não de alta gravidade, e que foi mudando de realidade com a chegada cada vez mais agressiva.

Quando de fato houve a aceitação principalmente por parte das autoridades, iniciou-se o enfrentamento do problema, como o fechamento de estabelecimentos, interdição de locais que eram de grande concentração de pessoas, suspensão de atividades escolares e esportivas; além de medidas de prevenção veiculadas na imprensa local com intenção de frear o surto epidêmico. Comparando Bragança com as demais cidades levantadas na literatura, podemos observar algumas semelhanças e peculiaridades no que se refere ao enfrentamento da doença. E assim, o mesmo jornal que anunciou a chegada da gripe em Bragança, divulgava a tiragem do mês de dezembro que a gripe já se findava, acalmando a população dessa grande e grave crise vivida na cidade.

\section{Referências}

ABREU JUNIOR, José Maria de Castro. O vírus e a cidade: Rastros da gripe espanhola no cotidiano da cidade de Belém (1918) 1.ed. - Belém [PA]: Paka-Tatu, 2018.

BERTOLLI FILHO, Claudio. A gripe espanhola na Bahia: saúde, política e medicina em tempos de epidemia. Rio de Janeiro: Editora Fiocruz/Salvador: Edufba; 2009. 
2003.

A gripe espanhola em São Paulo, 1918: epidemia e sociedade. São Paulo: Paz e Terra,

BERTUCCI, Liane Maria. A onipresença do medo na influenza de 1918. Varia hist. vol.25. n.42. Belo Horizonte. July/Dec. 2009.

Influenza, a medicina enferma: ciência e práticas de cura na época da gripe espanhola em São Paulo. Campinas, SP: Editora da Unicamp, 2004.

BRITO, Nara Azevedo. La dansarina: a gripe espanhola e o cotidiano na cidade do Rio de Janeiro. Hist. cienc. saúde-Manguinhos. vol.4 no.1 Rio de Janeiro Mar./June 1997.

BURKE, Peter. Uma história social do conhecimento: II: da Enciclopédia à Wikipédia. Rio de Janeiro: Zahar, 2012.

A Escola dos Annales: a Revolução Francesa da historiografia. São Paulo: UNESP, 1990.

CZERESNIA, D. Do contágio à transmissão: ciência e cultura na gênese do conhecimento epidemiológico. Rio de Janeiro: Editora FIOCRUZ, 1997.

O conceito de saúde e a diferença entre prevenção e promoção. Rio de Janeiro: Editora Fiocruz, 2013.

DAMACENA NETO, Leandro Carvalho. A “influenza espanhola” de 1918/1919 na cidade de Goiás. Dissertação apresentada ao Programa de Pós-Graduação em História, da Faculdade de História da Universidade Federal de Goiás.2011.

DALL'ANA. João Paulo, MOTA, André. A gripe espanhola em Sorocaba e o caso da fábrica Santa Rosália, 1918: contribuições da história local ao estudo das epidemias no Brasil. Hist. cienc. saúde-Manguinhos vol.24 no.2 Rio de Janeiro Apr./Jun. 2017.

DELUMEAU, Jean. História do medo no Ocidente 1300-1800: Uma cidade sitiada. São Paulo: Companhia das letras, 2009.

FARIAS, Eduardo Alexandre de. Jornalismo à espanhola: Um olhar sobre o noticiário recifense da epidemia de gripe de 1918. Dissertação apresentada ao Programa de Pós-Graduação em Comunicação da Universidade Federal de Pernambuco. 2008.

FERREIRA, Norma Sandra de Almeida. As pesquisas denominadas "estado da arte". Educ. Soc. [online]. 2002, vol.23, n.79, pp.257-272.

FOUCAULT, Michael. O Nascimento da Clínica. Rio de Janeiro: Forense- Universitária, 1977.

GAMA, Rosineide de Melo. Dias mefistofélicos: a gripe espanhola nos jornais de Manaus (1918 1919). Dissertação apresentada ao programa de Pós-Graduação em História pela Universidade Federal do Amazonas.2013.

GOULART, Adriana da Costa. Revisitando a espanhola: a gripe pandêmica de 1918 no Rio de Janeiro..Hist. cienc. saúde-Manguinhos. Vol.12. no.1. Rio de Janeiro. Jan./Apr. 2005.

HAMER, Sir W. Epidemiology: old and new. London. Kegan Paul,Trench, Trubner eCo., LTD, 1928.

LAURELL, Asa Cristina. A saúde-doença como processo social. Revista Latinoamericana de Salud, México, 2, pp. 7-25. 1982.

LE GOFF, Jacques (org). As Doenças tem história. Lisboa: Terramar, 1985.

MAHONY, Mary Ann. Epidemia como desafio sociopolítico: a gripe espanhola na Bahia. Hist. cienc. saúde-Manguinhos vol.19. no.4. Rio de Janeiro. Oct./Dec. 2012.

MARTINS, Maria José Moraes. Bacillus influenzai ou micrococcus catarrhalis? Controvérsias médicas durante a epidemia de gripe espanhola em Belém, 1918. Revista Estudos Amazônicos. vol. XI, $\mathrm{n}^{\circ} 2$ (2015).

NONATO DA SILVA. Dário Benedito Rodrigues. Os Donos de São Benedito: convenções e rebeldias 
na luta entre o catolicismo tradicional e devocional na cultura de Bragança. Século XX. Belém: Dissertação apresentada ao Programa de Pós-Graduação em História Social da Amazônia, 2006.

OLINTO, Beatriz Anselmo. Uma cidade em tempo de epidemia: Rio Grande e a gripe espanhola.1918. Florianópolis: Dissertação apresentada ao Programa de Pós-Graduação em História pela Universidade Federal de Santa Catarina, 1995.

PACKER, Abel L.; MENEGHINI, Rogério. O SciELO aos 15 anos: avanços e desafios para o futuro. In: PACKER, Abel L. et al. (Org.). SciELO - 15 anos de Acesso Aberto [livro eletrônico]: um estudo analítico sobre Acesso Aberto e comunicação científica. Paris: UNESCO, 2014.

ROSEN, G. Uma História da Saúde Pública. São Paulo/Rio de Janeiro: Hucitec/Unesp/Abrasco, 1994.

SANTOS, C. M. Tradições e Contradições da pós-graduação no Brasil. Educ. Soc. Campinas, vol. 24, n 83. 627-641, agosto 2003.

SOUZA, Christiane Maria Cruz de. A "espanhola" em Salvador: o cotidiano da cidade doente. Varia hist. vol.25. no.42. Belo Horizonte. July/Dec. 2009.

A gripe espanhola na Bahia: saúde, política e medicina em tempos de epidemia. Hist. cienc. saúde-Manguinhos. Vol.14. no.3. Rio de Janeiro. July/Sept. 2007.

As dimensões político-sociais de uma epidemia: a paulicéia desvairada pela gripe espanhola. Hist. cienc. saúde-Manguinhos. Vol.12. no.2. Rio de Janeiro. May/Aug. 2005.

A gripe espanhola em Salvador, 1918: cidade de becos e cortiços. Hist. cienc. saúde-Manguinhos.vol.12. no.1. Rio de Janeiro. Jan./Apr. 2005.

SANTOS, Ricardo Augusto dos. O Carnaval, a peste e a 'espanhola'. Hist. cienc. saude-Manguinhos. vol.13. no.1. Rio de Janeiro. Jan/Mar. 2006.

SILVEIRA, Anny Jackeline Torres. A medicina e a influenza espanhola de 1918- Tempo. Vol.10. no.19. Niterói. Jul./Dec. 2005.

SILVEIRA, Anny Jackeline Torres e NASCIMENTO, Dilene Raimundo do. A doença revelando a história. Uma historiografia das doenças. In: NASCIMENTO, Dilene Raimundo do \& CAVARLHO, Diana Maul de (orgs). Uma história brasileira das doenças. Brasília: Paralelo 15, 2004.

SILVA, Júlio Santos da. Adoecendo na cidade da borracha: Manaus (1877-1920). Manaus: Dissertação apresentada ao Programa de Pós-Graduação em História da Universidade Federal do Amazonas, 2012.

SONTANG, Susan. Doença como metáfora. Aids e suas metáforas. São Paulo: Companhia de bolso, 2007.

Artigo recebido em: 29/10/2019

Artigo aceito em: 10/02/2020 